\title{
Experimental Study on a Forced-Circulation Loop Thermosiphon Solar Water Heating System
}

\author{
Tao Zhang $\mathbb{D}$ \\ School of Energy and Mechanical Engineering, Shanghai University of Electric Power, Shanghai 200090, China \\ Correspondence should be addressed to Tao Zhang; zhtyn86@163.com
}

Received 16 January 2018; Accepted 29 April 2018; Published 5 July 2018

Academic Editor: Alberto Álvarez-Gallegos

Copyright ( 2018 Tao Zhang. This is an open access article distributed under the Creative Commons Attribution License, which permits unrestricted use, distribution, and reproduction in any medium, provided the original work is properly cited.

\begin{abstract}
Wickless gravity loop thermosiphons (LTs) have been widely used in heat collection for distances up to several meters. This twophase closed device, which is operating under reduced pressure, is useful in solar water heating (SWH) systems because it could address the freezing problem during winter. Compared to the normal type, forced-circulation wickless LTs have significant advantages in the long-distance heat transfer and installation freedom of condensation section. In this study, a pump-forced wickless LT-SWH system with a remolded flat-plate solar collector was put forward. Solar collector acted as the evaporation section of the wickless LT, while the spiral heat exchanger in the water tank acted as the condensation section. R600a was employed as the working fluid, and long-term outdoor experiments were carried out. Results show that the instantaneous and daily average photothermal efficiency of the proposed system can reach $69.54 \%$ and $58.22 \%$, respectively. Temperature differences between the top and bottom and the middle and bottom of the evaporation section of the wickless LT were small, and it usually ranged between 1.1 and $3.9^{\circ} \mathrm{C}$. Linear fittings of the collector and system overall performance of the pump-forced wickless LT-SWH system demonstrate the promising potential application of the system.
\end{abstract}

\section{Introduction}

Solar water heating (SWH) systems have been widely applied in both domestic and industrial levels, and SWHs have been proven to be readily available technologies that can directly substitute renewable energy for conventional water heating. Based on the type of involved circulation, the SWHs can be categorized into two groups: natural circulation and forced circulation. Different circulation types of the SWH systems are expected to be available and suitable for different applications [1, 2]. Forced-circulation SWHs are usually used in commercial and industrial heat processing [3]. The solar collector is of great importance and works as the heart of the SWH system. The most diffused solar technologies are evacuated tube collectors in China and are flat-plate solar collectors in the rest of world [4]. However, for a conventional flat-plate solar collector, there are freezing problems when the ambient temperature is lower than zero, as well as corrosion problems when the water temperature is high and the $\mathrm{pH}$ departs from the neutral level [5].
Loop thermosiphons (LTs) [6], vapordynamic thermosiphons (VDTs) $[7,8]$, and pulsating heat pipes (PHPs) [9] are alternative solutions to the aforementioned problems. Among these heat transfer devices, LTs are most appreciated when integrating with solar collector for the simple manufacturing process. LT is a two-phase closed device that provides an alternative solution to the aforementioned problems. The evaporation and condensation sections of a LT are separated; thus, it can realize effective and remote heat transfer with the assistance of capillary pumping or gravity $[10,11]$. It has excellent heat transfer characteristic due to the vacuum seal and phase-change heat transfer. It also has excellent isothermal characteristics on the basis of inner two-phase heat transfer. The LT-SWHs have been intensively investigated in recent decades. Soin et al.'s $[12,13]$ experiments examined the photothermal performance of a LT solar evaporator charged with acetone and petroleum ether. The photothermal efficiency of the two-phase solar collector was only approximately $6 \%-11 \%$, which was lower than that of a water-based SWH system. M. Esen and H. Esen [14] 


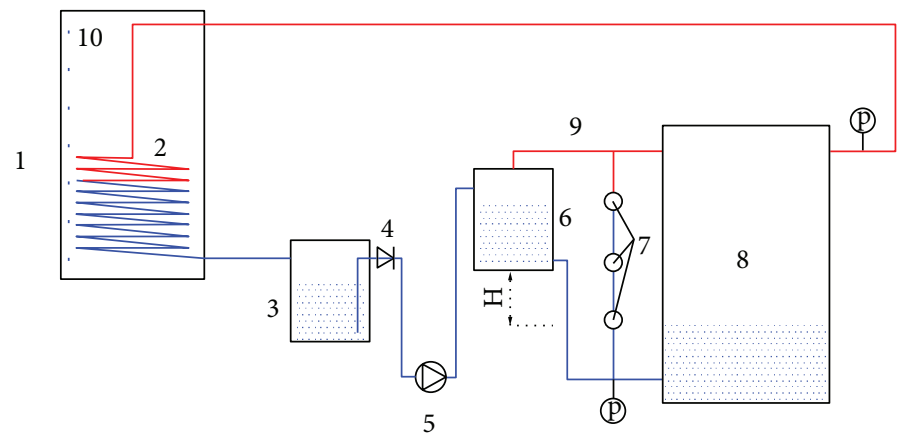

FIGURE 1: Schematic of the forced-circulation wickless LT-SWH system. (1) Water tank, (2) condensation spiral coil pipe, (3) condensation liquid storage tank, (4) check valve, (5) refrigerant pump, (6) evaporation liquid storage tank, (7) sight glass, (8) evaporation solar collector, (9) pressure balance pipe, (10) thermocouples

investigated the thermal performance of a LT solar collector by using different working fluids. Results showed that all of them had a similar maximum collection efficiency of around 50\%. Chien et al. [15] developed a theoretical model validated with experimental data; the result indicated that the best instantaneous thermal efficiency was $82 \%$, which was higher than that of conventional SWH systems. Joudi and Al-tabbakh [16] also revealed that the photothermal efficiency of a LT-SWH system was approximately $20 \%$ higher than that of a water-based collector. Arab et al. [17] employed pulsating heat pipes (PHPs) in a SWH system. An extra-long PHP was designed, and the results showed that the configuration achieves satisfactory performance. Mathioulakis and Belessiotis [18] theoretically and experimentally presented their investigations on the energy behavior of a new type of solar collector that uses a wickless LT filled with ethanol. An instantaneous efficiency of up to $60 \%$ was observed. Hussein $[19,20]$ presented a theoretical and experimental analysis of a LT flat-plate solar water heater. Different meteorological conditions, initial water tank temperatures, hot water withdrawal load patterns, ratios of the storage tank volume to the collector area, storage tank dimension ratios, and height of the heater storage tank and collector were examined. Ordaz-Flores et al. [21] presented the indirect performance of a LT-SWH system using acetone and methanol as the working fluids. The results showed that the average experimental photothermal efficiencies during the test day were $48 \%$ and $50 \%$, respectively. Zhang et al. [22] used supercritical $\mathrm{CO}_{2}$ as the working fluid; an average collecting efficiency of $58 \%$ during whole-year tests was presented. Pei et al. [23] compared a LT-PV/T collector and a normal PV/T collector by using R600a as the working fluid. The results showed that the LT-PV/T collector had higher photovoltaic conversion efficiency but lower photothermal efficiency and a smaller temperature difference among the cells of the collector than the normal PV/T collector. However, both systems showed almost the same energy efficiency. Albanese et al. [24] presented a heat pipe-assisted solar wall, and experimental and computer models were developed to evaluate the performance of the system. Some studies using LT on the BIPV/T system are also presented. Zhao et al. [25] theoretically investigated the performance of an LT-SWH for a typical apartment building in Beijing.
The relationship between the efficiency of the system and the operating parameters was established, analyzed, and discussed in detail. Wang et al. [26] examined a novel facadebased solar LT water heating system by using both theoretical and experimental methods. Various operational parameters and two types of glass cover were discussed. The experimental and simulated results were in good agreement.

The two-phase circulation flow in the LTs is driven by the temperature difference with the assistance of gravity or the capillary force. The wick situated in the evaporator is normally made by the porous structure, which needs a complex and expensive manufacturing process. It produces the capillary force to drive the liquid back to the evaporator and ensures that the working liquid is evenly distributed over the heat transfer surface in the evaporator. However, it is costly to set up wicks in the copper tubes behind a flat-plate solar collector.

Considering that the solar collectors are usually inclined and installed, a wickless gravity-assisted LT is more preferred due to its low cost and simple structure. Nevertheless, the wickless LT-SWH system cannot be used when the water tank is lower than the solar collector, which means it is hard to integrate with buildings and is not suitable for household using. Learning from the active-cycle water-based SWHs, a refrigerant pump can be introduced to a wickless LT-SWH system. Although the system requires additional power consumption, the water tank has no position limitation, the pipes have no length limitation, and the system can be easily integrated into the buildings. However, few experiments or tests about the forced-circulation wickless LT-SWH system have been conducted. The forced-circulation wickless LT-SWH is new and the system behavior has yet to be reported. Therefore, in this study, a prototype of the novel forced-circulation wickless LT-SWH system is initially proposed. It consists of a refrigerant pump, an evaporation solar collector, a condensation water tank, an evaporation liquid storage tank, and a condensation liquid storage tank. A long-term outdoor test was performed; system performance was studied.

\section{System Design and Experiment Setup}

The schematic of the proposed system is shown in Figure 1. It comprises a solar collector acting as the evaporation section 
TABLE 1: Detailed information of the parts and the copper pipes.

\begin{tabular}{|c|c|c|}
\hline $\begin{array}{l}\text { Device and the } \\
\text { copper tube }\end{array}$ & $\begin{array}{l}\text { Dimension } \\
(\mathrm{mm})\end{array}$ & Remarks \\
\hline Water tank & $\Phi 450 * 1570$ & $150 \pm 1 \mathrm{~L}$ \\
\hline $\begin{array}{l}\text { Condensation fluid } \\
\text { storage tank }\end{array}$ & $\Phi 58 * 440$ & $5.9 \mathrm{~L}$ \\
\hline $\begin{array}{l}\text { Evaporation fluid } \\
\text { storage tank }\end{array}$ & $\Phi 58 * 440$ & $5.9 \mathrm{~L}$ \\
\hline Pump & I & $60 \mathrm{~W}$ (rated power) \\
\hline $\begin{array}{l}\text { Solar collector } \\
\text { (water-based) }\end{array}$ & $\begin{array}{l}1000 * 2000 \\
\quad * 95\end{array}$ & $\eta=0.751-4.206\left(\left(T_{\mathrm{ic}}-\bar{T}_{\mathrm{a}}\right) / G\right)$ \\
\hline \multirow{2}{*}{ Absorber plate } & $1960 * 950 *$ & Absorption rate $\geq 0.95$ \\
\hline & 0.4 & Emissivity $\leq 0.05$ \\
\hline Vapor pipe & $\Phi 28 * 1000$ & I \\
\hline Connection pipe & $\Phi 4$ & I \\
\hline $\begin{array}{l}\text { Condensation } \\
\text { spiral coil pipe }\end{array}$ & $\Phi 12 * 18000$ & l \\
\hline Sight glass & I & Emerson \\
\hline
\end{tabular}

of LT, an evaporation liquid storage tank, a condensation liquid storage tank, a water tank with a spiral coil pipe functioning as the condensation section of LT, four sight glasses, and a refrigerant pump. Information about the devices and the copper pipes used are presented in detail in Table 1. R600a was employed as the working fluid.

Refrigerant pump supplies fluid from the condensation liquid storage tank to the evaporation liquid storage tank. The condensation liquid storage tank collects and separates the condensed fluid and vapor to avoid idling of the pump. The pressure balance pipe has two functions. When the pump is working, extra pressure is exerted to the refrigerant, it disturbs the intrinsic evaporation process occurring in the solar collector, and exacerbates the oscillatory heat transfer of the loop thermosiphon. The pressure balance pipe can mitigate the fluctuation caused by the pump. Besides, pressure difference comes up between the top and the bottom of the solar evaporator; the pressure balance pipe can promote the refrigerant flow with the aid of it. When the pump is not working, the refrigerant evaporates when there are solar irradiation incidents upon the solar collector, which will raise the inner pressure of the evaporator. The refrigerant in the evaporation liquid storage tank cannot flow down when the pressure is big enough. The pressure balance pipe can avoid this and ensures the R600a liquid continuously flows down by gravity. The evaporated R600a vapor will be condensed by the water and collected in the condensation liquid storage tank.

By using the pump, the water tank can be flexibly installed, which means the system can be easily integrated with the building. The check valve prevents the reverse flow of the fluid when the pump stops. Cycle process of the system is as follows: firstly, incident solar irradiation is absorbed by the absorber plate; soon afterwards, the heat energy of the absorber plate is absorbed by the R600a fluid, which vaporizes the fluid; then, R600a vapor flows along the vapor pipe to the spiral coil in the water tank, wherein it is to be condensed into liquid and finally flows to the condensation liquid storage tank. The evaporation liquid storage tank acts as the liquid supplement of the solar collector, whereas the pump acts as the supplement for the evaporation liquid storage tank.

The experiments were all outdoor tested in Hefei City $\left(31.52^{\circ} \mathrm{N}, 117.17^{\circ} \mathrm{E}\right)$. The height of the water tank, condensation fluid storage tank, and evaporation storage tank were $150 \mathrm{~mm}, 500 \mathrm{~mm}$, and $1050 \mathrm{~mm}$ above the ground, respectively. The solar collector, with an inclination of $40^{\circ}$, was installed facing south. With the consideration of working tilt angle of the wickless LT evaporation section, the collector inclination was a little bigger than the city latitude. Pressures of solar collector liquid inlet and vapor outlet were measured. The straight-line distances between the sight glasses' location and the bottom edge of the collector were $350 \mathrm{~mm}, 750 \mathrm{~mm}$, $1150 \mathrm{~mm}$, and $1550 \mathrm{~mm}$. The sight glasses, as well as the pyranometer, were parallelly installed to the collector. Seven T-type thermocouples were arranged to measure the water temperature variation. A frequency modulator was employed to adjust the flow rate, and a power sensor was used to measure the pump and modulate the power consumption. The thermocouples were set at the back of the copper pipes, surface and back of the absorber plate, and surface of the glass cover. Figure 2 presents the system physical setup and thermocouple setup on the copper pipes. Ambient temperature, as well as solar irradiation, was also recorded. All the measured data were recorded through Agilent 34970A. Precisions of the devices are listed in Table 2. The R600a mass charge of the system was $4.05 \mathrm{~kg}$, which means the R600a volume filling ratio of the whole volume was $50 \%$. The experiments were carried out from 8:00 to 16:00. The flow of the pump was set at $571.2 \mathrm{~mL} / \mathrm{min}$ (theoretical, the same followed) from 8:00 to 9:00, $761.6 \mathrm{~mL} / \mathrm{min}$ from 9:00 to $10: 00,952 \mathrm{~mL} / \mathrm{min}$ from $10: 00$ to $14: 00,571.2 \mathrm{~mL} / \mathrm{min}$ from $14: 00$ to $15: 00$, and $380.8 \mathrm{~mL} / \mathrm{min}$ from $15: 00$ to $16: 00$.

The maximum volume flow rate of the refrigerant is estimated based on the following assumptions:

(1) The maximum solar irradiation at noon is $1000 \mathrm{~W} / \mathrm{m}^{2}$.

(2) The collector efficiency is $75 \%$, the same as the efficiency provided by the manufacturer.

(3) The R600a liquid and vapor in the solar evaporator are both under saturation state; it means that all the absorbed energy is converted to the R600a latent heat.

(4) The values of the physical property parameters of $\mathrm{R} 600 \mathrm{a}$ are based on the temperature of $30^{\circ} \mathrm{C}$.

(5) The values of the physical property parameters of R600a vapor and liquid are constant when calculating the pressure loss.

(6) The values of the flow rate at other time periods are estimated based on the photothermal performance of the gravitative loop thermosiphon. 


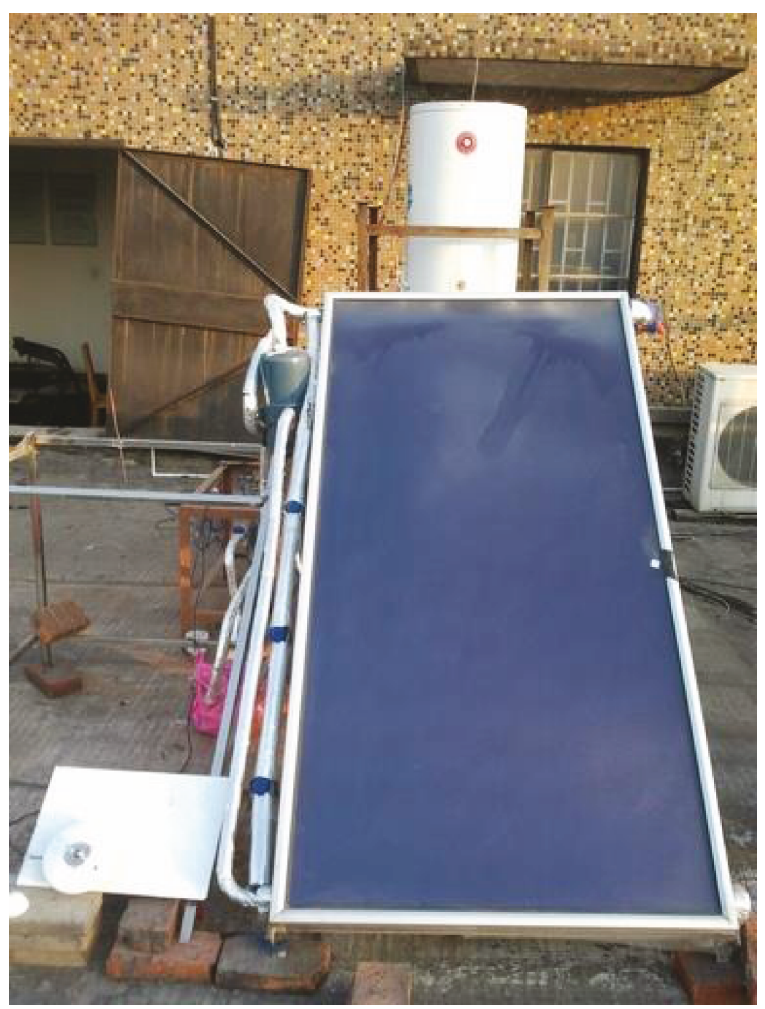

(a)

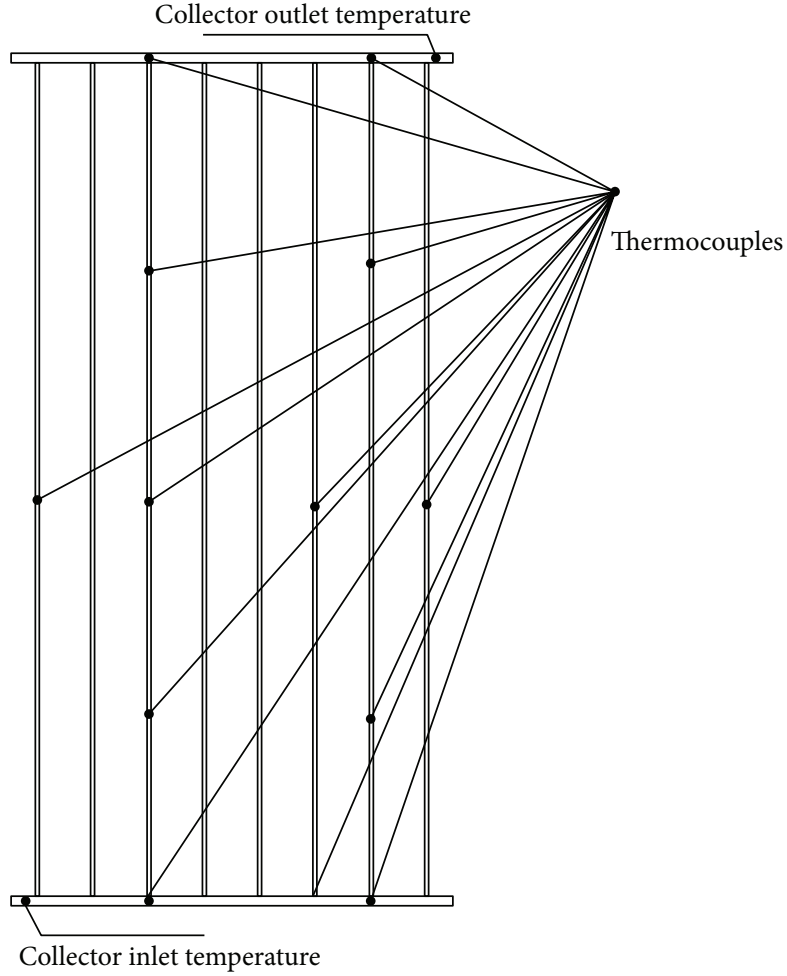

(b)

FIgURE 2: System physical setup and the detailed locations of the thermocouples' setup.

TABle 2: Manufacturers, models, and precisions of monitoring devices.

\begin{tabular}{lcc}
\hline Device & Specification & Precision \\
\hline Power sensor & $\begin{array}{c}\text { WBI021S91 } \\
\text { (Weibo, China) }\end{array}$ & $0.5 \%$ \\
Pyranometer & $\begin{array}{c}\text { TQB-2 } \\
\text { (Sunlight, China) }\end{array}$ & $\leq 2 \%$ \\
Thermocouple & $\begin{array}{c}0.2 \mathrm{~mm} \text { T-type } \\
\text { (USTC, China) }\end{array}$ & $\pm 0.2^{\circ} \mathrm{C}$ \\
Data collection & $\begin{array}{c}34970 \mathrm{~A} \\
\text { (Agilent, USA) } \\
\text { Pressure sensor }\end{array}$ & P3308 \\
\hline
\end{tabular}

\section{System Evaluations and Error Analysis}

The daily performance of the water-based SWH system is evaluated with the daily average efficiency, which is expressed as

$$
\eta_{\text {sys }}=\frac{C M\left(T_{\mathrm{f}}-T_{\mathrm{i}}\right)-W_{\mathrm{p}} t}{H A},
$$

where $C$ is the water specific heat, $\mathrm{J} /(\mathrm{kg} \cdot \mathrm{K}) ; M$ is the water mass in the water tank, $\mathrm{kg} ; T_{\mathrm{f}}$ and $T_{\mathrm{i}}$ are the final and initial water temperature in the water tank, respectively, ${ }^{\circ} \mathrm{C} ; W_{\mathrm{p}}$ is the power of the pump, $\mathrm{W}$; $t$ is the working time, $s ; H$ is the total or average incident solar irradiation on the surface of glass cover during the experiment, $\mathrm{J} / \mathrm{m}^{2}$; and $A$ is the aperture area of the collector, $\mathrm{m}^{2} . T_{\mathrm{i}}$ and $T_{\mathrm{f}}$ in this study are the average values of the thermocouples in the water tank. System daily average photothermal efficiency can also be calculated according to (1), where $H$ is the accumulation of solar irradiation of the whole day.

Photothermal performances of water-based SWH systems are affected by many factors, including solar irradiation, system design, environment temperature, collector inclination, wind speed, and initial water temperature. A method to evaluate the natural convection performance for a waterbased SWH system is suggested by Huang and Du [27]. It is expressed as

$$
\eta^{*}=\alpha-U \frac{T_{\mathrm{i}}-\overline{T_{\mathrm{a}}}}{H^{*}},
$$

where $\eta^{*}$ is the estimated system photothermal efficiency; $\overline{T_{\mathrm{a}}}$ is the average ambient temperature, ${ }^{\circ} \mathrm{C}$; $\alpha$ is the typical photothermal efficiency when $T_{\mathrm{i}}$ equals $\overline{T_{\mathrm{a}}} ; U$ is the system heat loss coefficient; and $H^{*}$ is the daily total solar irradiation per area, $\mathrm{MJ} /\left(\mathrm{m}^{2}\right.$.day $)$. Equation (2) is also used to estimate the proposed system performance in this study.

The same method as that used in (2) is applied to evaluate the collector performance $\eta_{\text {col }}^{*}$, where $T_{\mathrm{i}}$ is the initial R600a fluid temperature that returns to the collector, ${ }^{\circ} \mathrm{C}$, and $H^{*}$ is the average solar irradiation during different time periods, $\mathrm{W} / \mathrm{m}^{2}$. 
Inaccuracies in the test devices will cause some errors in the test data. The test error of the independent variables, such as the solar radiation intensity, water mass, and temperature, is determined based on the accuracy of the corresponding test devices in this study. For the dependent variables, such as the collector and system photothermal efficiencies, their test errors can be confirmed based on the test error of the independent variables. Given a dependent variable $y$, its function can be expressed as follows:

$$
y=f\left(x_{1}, x_{2} \ldots x_{n}\right),
$$

where $x i(i=1, \ldots, n)$ is the variable of the function.

Then, the relative error (RE) of the dependent variable can be confirmed as follows [28]:

$$
\mathrm{RE}=\frac{d y}{y}=\frac{\partial f}{\partial x_{1}} \frac{d x_{1}}{y}+\frac{\partial f}{\partial x_{2}} \frac{d x_{2}}{y}+\cdots+\frac{\partial f}{\partial x_{n}} \frac{d x_{n}}{y},
$$

where $\partial f / \partial x_{1} i$ is the error transferring coefficient of the variables. Therefore, the experimental relative mean error (RME) during the test period can be calculated as

$$
\mathrm{RME}=\frac{\sum_{1}^{N}|\mathrm{RE}|}{N} .
$$

Based on (4) and (5), the RMEs of the independent and dependent variables are calculated, and the details are presented in Table 3.

\section{Experimental Results and Discussions}

4.1. Details of Daily Performance of the System. To present the details of the daily performance of the system, a typical day is selected. The ambient environment, including the ambient temperature and solar irradiation fluctuation on that day, is illustrated in Figure 3. Total solar irradiance was $22.7 \mathrm{MJ} / \mathrm{m}^{2}$ on that day, and the average ambient temperature was $20.5^{\circ} \mathrm{C}$.

4.1.1. Instantaneous Photothermal Performance. Variations of the instantaneous photothermal efficiency (calculated based on (1) every $30 \mathrm{~min}$ ) and average water temperature are shown in Figure 4. Photothermal efficiency firstly increases and then decreases. The highest instantaneous photothermal efficiency was registered at 10:15, with a value of $69.54 \pm 11.10 \%$, which was better than the work of M. Esen and H. Esen [14] and Mathioulakis and Belessiotis [18], whereas the lowest photothermal efficiency was recorded at the end of the test, with a value of $28.77 \pm 15.77 \%$.

System photothermal performance is determined by the heat energy absorbed by the solar collector. The combined action of absorptivity and heat loss of the absorber plate determines the effective heat gain. The absorptivity of the absorber plate is mainly determined by the transmittance of glass when the coating is fixed. The heat loss is mainly determined by the temperature difference between the absorber plate and ambient. Before 10:30, the temperature difference between the water and environment, positive or negative, was small. The transmittance of the glass increased with the incident angle decreased and thereby increased photothermal
TABLE 3: Experimental RMEs of all variables.

\begin{tabular}{lccccc}
\hline Variable & $T_{\mathrm{w}}$ & $H$ & $M^{*}$ & $\eta_{\text {sys }}$ & $\eta_{\text {col }}^{*}$ \\
\hline RME & $0.062 \%$ & $2 \%$ & $0.667 \%$ & $4.013 \%$ & $22.818 \%$ \\
\hline
\end{tabular}

${ }^{*} M$ is the water mass in the water tank.

efficiency. Between 10:30 and 14:15, although the temperature difference was relatively large and resulted in substantial heat loss, the efficiency slowly decreased with the help of a larger irradiation density and a smaller solar incident angle. After 14:15, the efficiency was sharply decreased because the temperature difference as well as the incident angle was absolutely large. An average efficiency of $58.22 \pm 12.81 \%$ was obtained on this day, which was higher than the value obtained in the works of Arab et al. [17] and Ordaz-Flores et al. [21] and was similar to that of Zhang et al. [22].

The water temperature gradually increased from $11.5^{\circ} \mathrm{C}$ to $49.7^{\circ} \mathrm{C}$ during the test, but it presented a different growth gradient in different times. One can see from Figure 4 that the growth gradient was gradually increased during the first two hours, then stable and sustained in the following four hours, and gradually decreased in the last two hours. The fluctuation trend can be explained similar to that of the instantaneous photothermal efficiency. During the first two hours of the test, the solar irradiation was weak and the temperature difference between the absorber plate and the surrounding was small; the growth gradient increased with the transmittance of the glass increased;. During the middle time of the test, the stronger solar irradiation and bigger glass transmittance caused the quick rising of temperature. During the last two hours, the growth gradient decreased with the photothermal efficiency decreased.

Figure 5 qualitatively describes the liquid level of the solar evaporator. Note that it only presents the relative location of the liquid level, not the concrete values. As shown in Figure 5, the liquid level was usually low in the beginning of the test; the reason was that when the pump stopped working in the end of the last test, no fluid entered into the solar evaporator after that; however, the R600a liquid will be slowly evaporated after the last test and before this test, although the solar irradiation at these times was weak. The liquid level gradually raised when the pump began to work and then stayed nearby the second sight glass for about 3 hours; after that, the liquid level began to raise and continued to raise until the end of test, although the pump had turned down two times; the liquid level finally reached to a height higher than the fourth sight glass, that is, the evaporation liquid storage tank was full of R600a liquid at the end of the test.

As shown in Figure 5, one can also observe that the variation of the pump power was segmented by the set of flow rate. The pump flow rate was adjusted five times during the test; the pump power was presented five changes also, and it can be easily observed that the pump power was relatively stable under the same flow rate. Based on the test data, an average power of $29.64 \mathrm{~W}$ was obtained on that day.

According to Zhao et al. [25], the loop thermosiphon has the best filling ratio that lies between $30 \% \sim 50 \%$ of the whole volume and has a negative performance when overcharged. 


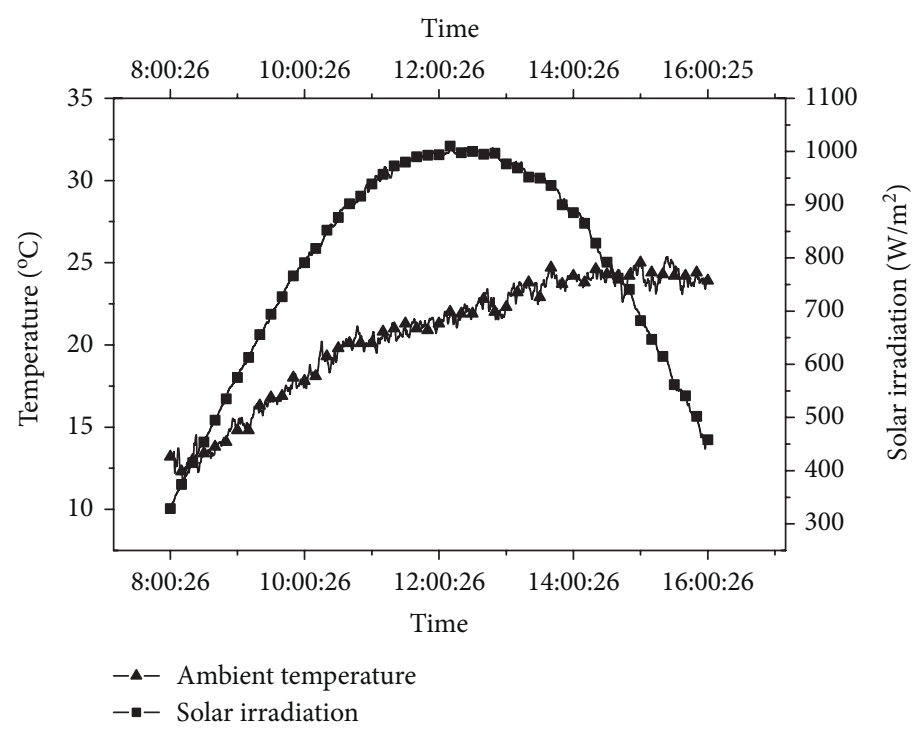

Figure 3: Variations in ambient temperature and solar irradiation on the typical day.

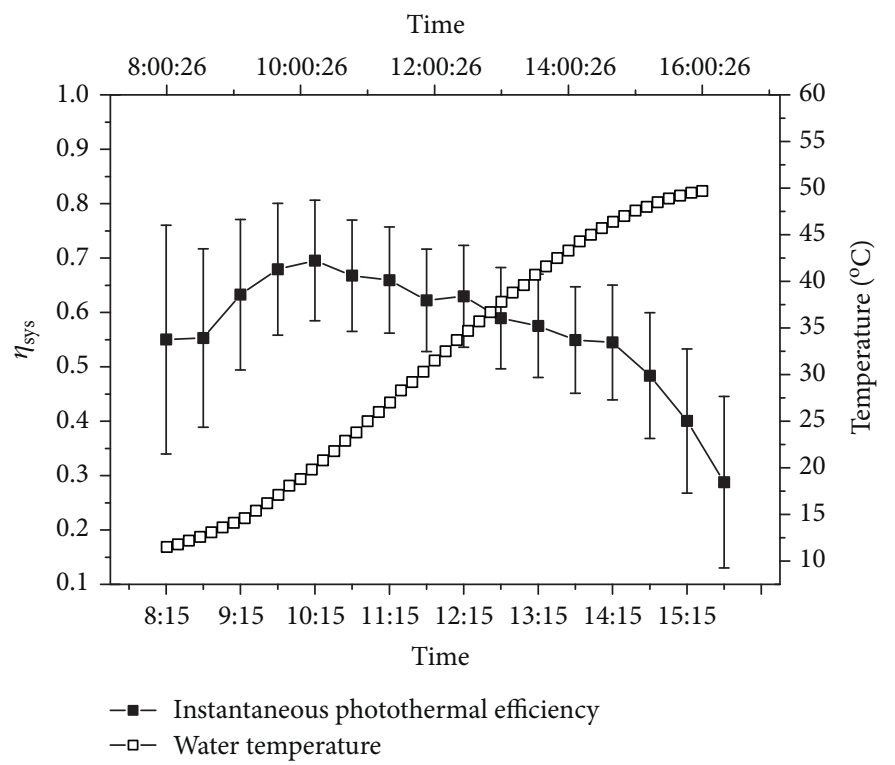

FIGURE 4: Variations in instantaneous photothermal efficiency and water temperature.

The higher the filling ratio, the smaller the photothermal efficiency achieved and the lower the efficiency fluctuation presented. Although the volume filling ratio in this study used the previous optimal result, the existence of the pump, condensation liquid storage tank, and evaporation liquid storage tank made the actual evaporation liquid level higher than Zhao et al. [25] under the same filling ratio; since the condensation liquid storage tank and evaporation liquid storage tank contribute a big amount of volume; however, those parts had limited contributions on the overall heat transfer.

At the same time, as shown in Figure 1, according to Aung and Li [30], the driving force for the circulation of working fluid in a loop thermosiphon system is mainly related to hydraulic head between the highest liquid level in the liquid return pipe and evaporation liquid level in the solar collector. From Figure 5 and the location of the evaporation liquid storage tank, one can conclude that a high liquid level also means a small hydraulic head. Therefore, the high position of the evaporation liquid storage tank will be beneficial or it can change to a slender one. Since a certain amount of volume should be provided to avoid solar collector drying out at the end of the test or at the beginning of the next test, depth-width ratio of the evaporation liquid storage tank and pump flow rate control should be further optimized. Besides, the location of the evaporation liquid storage tank and its influences on the system photothermal performance, system integrability, and convenience of installation should also be considered. 


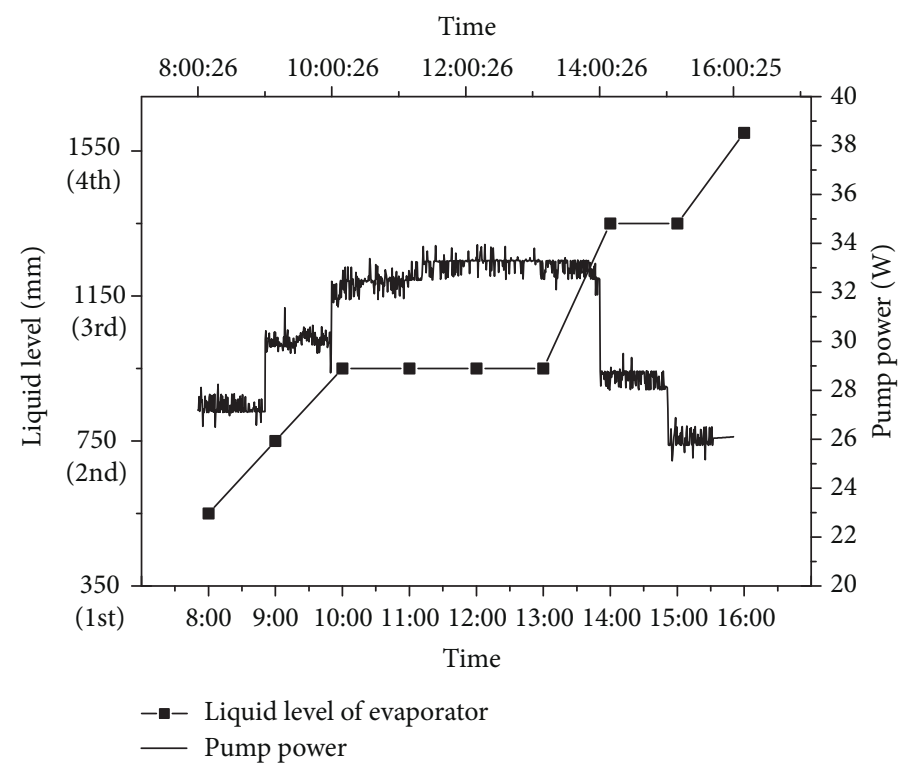

FIGURE 5: Qualitative variation of the liquid level of the evaporator and pump power.

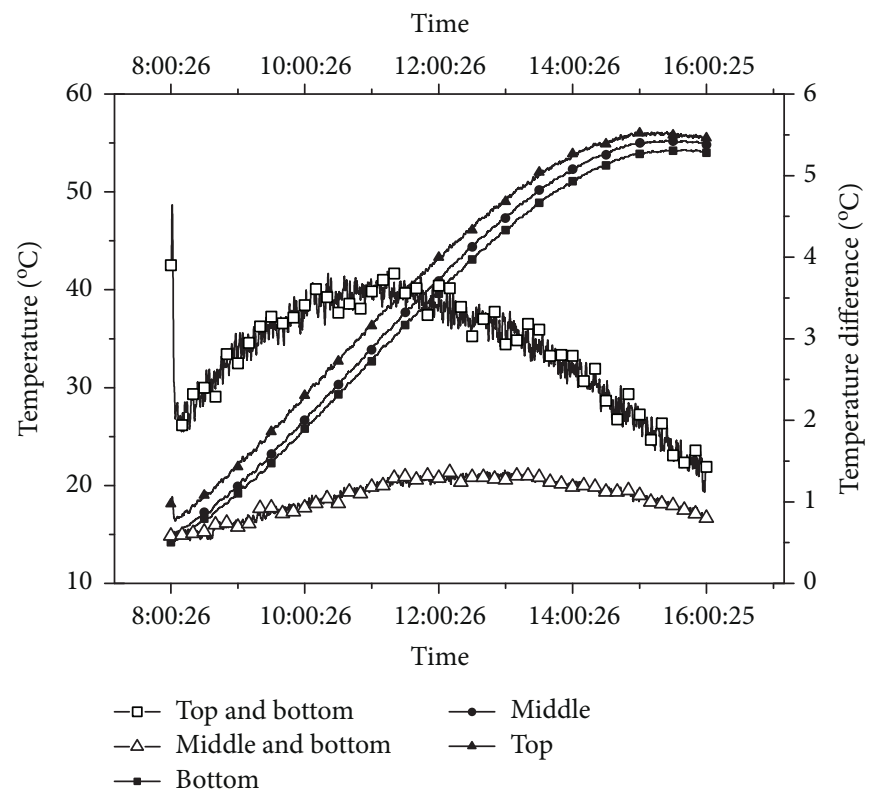

FIGURE 6: Variations in the bottom, middle, and top temperatures of the LT evaporation section and the temperature difference between the top and bottom parts of the LT.

To sum up, the instantaneous photothermal efficiency no less than the previous passive LT-SWH system was achieved. Although there was additional power consumption, the water tank has no location limited, which made the forced wickless LT-SWH easier integrated with buildings. However, system design, including the pump flow rate and evaporation liquid storage tank location, still has to be further optimized.

4.1.2. Temperature Performance of the Solar Collector. Isothermality of the evaporation section is one of the most significant characteristics of the loop thermosiphon. Thermocouples were placed to monitor it and to investigate the influence of the existence of the pump. The temperatures of the points, displayed on the right side of Figure 2, at bottom, middle, and top of the solar evaporation section (i.e., solar collector) were recorded. Average temperatures of the points at the same height are presented in Figure 6. Temperature differences between the top and bottom and middle and bottom are also plotted in Figure 6 to show the isothermality of the LT evaporation section.

From Figure 6, one can see that the collected temperatures at the bottom, middle, and top of the solar evaporator were all gradually increased with time; it was because the condensing temperature was gradually increased with time; 


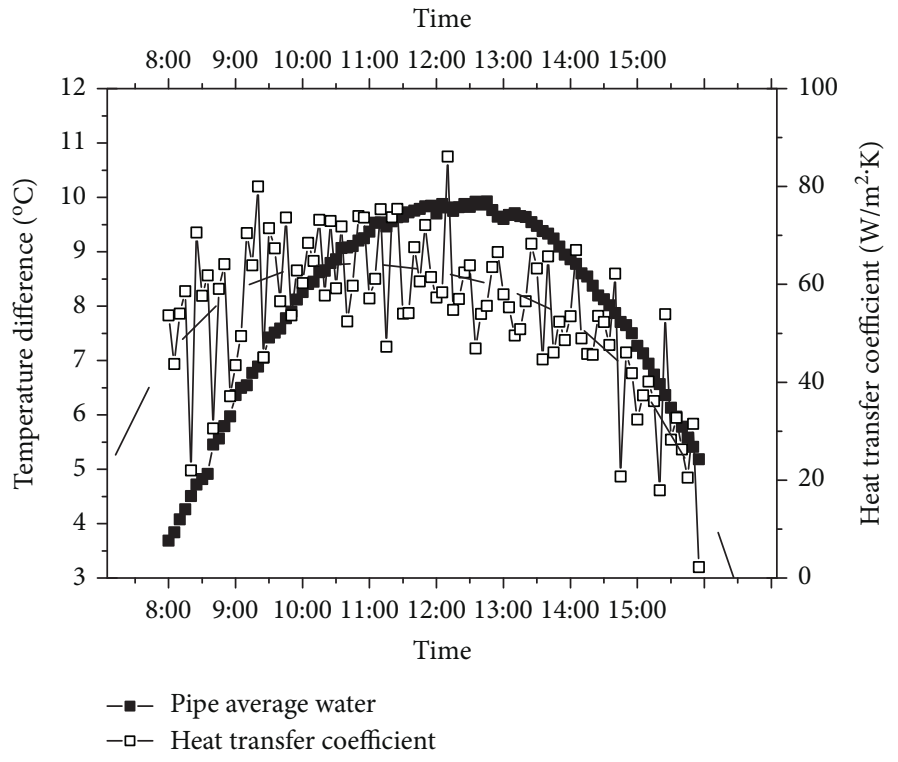

Figure 7: Variations in the heat transfer temperature difference and heat transfer coefficient.

TABle 4: Experimental results for collector performance linear fitting.

\begin{tabular}{lcccc}
\hline Time & $T_{\mathrm{ic}}{ }^{\circ} \mathrm{C}$ & ${\overline{T_{\mathrm{a}}}}^{\circ} \mathrm{C}$ & $G\left(\mathrm{~W} / \mathrm{m}^{2}\right)$ & $\eta_{\text {col }}(\%)$ \\
\hline $9: 45$ & 21.9 & 17.214 & 745.698 & 0.679 \\
$10: 15$ & 25.2 & 18.724 & 831.796 & 0.695 \\
$10: 45$ & 28.8 & 20.2 & 908.420 & 0.668 \\
$11: 15$ & 32.3 & 20.5 & 960.682 & 0.659 \\
$11: 45$ & 36.0 & 21.2 & 990.689 & 0.622 \\
$12: 15$ & 39.4 & 21.7 & 998.936 & 0.630 \\
$12: 45$ & 42.8 & 22.3 & 994.909 & 0.590 \\
$13: 15$ & 45.8 & 23.3 & 966.365 & 0.575 \\
$13: 45$ & 48.8 & 23.9 & 921.590 & 0.549 \\
$14: 15$ & 51.1 & 24.1 & 843.782 & 0.545 \\
$14: 45$ & 52.8 & 24.1 & 748.462 & 0.484 \\
\hline
\end{tabular}

the temperature differences between the top and bottom and middle and bottom both firstly increased and then decreased. The absorbed solar energy before the test began was responsible for the big temperature difference between the top and bottom at the beginning of the test; the solar collector that was immersed in the two-phase region was responsible for the small temperature difference between the middle and bottom. The temperature difference between the top and bottom with the maximum and minimum values was $3.9^{\circ} \mathrm{C} \pm 0.4^{\circ} \mathrm{C}$ and $1.1^{\circ} \mathrm{C} \pm 0.4^{\circ} \mathrm{C}$, respectively, while the values were $1.4^{\circ} \mathrm{C} \pm 0.4^{\circ} \mathrm{C}$ and $0.5^{\circ} \mathrm{C} \pm 0.4^{\circ} \mathrm{C}$ between the middle and bottom.

In Figure 6, it can be observed that the temperature difference between the top and the bottom of the collector presented a similar trend compared to the instantaneous photothermal efficiency, both had a trend of increased firstly and then decreased, and both deserved a maximum value around 10:30. At the beginning of the test, the low liquid level caused a high degree of superheat between the top and the bottom of the collector, and the value increased with the solar irradiation increased. At the end of the test, the value of superheat degree decreased with the solar irradiation decreased and liquid level increased.

However, the temperature difference between the middle and the bottom of the collector was always small, because the liquid level of R600a was around the middle or top position of the collector most of the time.

The daily average temperature differences between the top and bottom and middle and bottom were $2.8 \pm 0.4^{\circ} \mathrm{C}$ and $1.1 \pm 0.4^{\circ} \mathrm{C}$, respectively. Note that the $\mathrm{R} 600 \mathrm{a}$ vapor at the middle and top was under different dryness; heat resistance between the copper pipe and the R600a vapor at the top was higher than that of the middle. Therefore, it can be found that the collector temperature was almost evenly distributed.

4.1.3. Heat Transfer Coefficient of Pump-Forced Wickless LT. The performance of the forced wickless LT will directly influence the system performance; therefore, the heat transfer coefficient of the forced wickless LT is calculated and plotted in Figure 7. The $\Delta T$ is assumed as the temperature difference between the copper pipe and the water here; the copper pipe temperature is assumed as the average value of all the thermocouples pasted on the pipes (see Figure 2), and the water temperature is assumed as the average value of the thermocouples in the water tank.

As shown in Figure 7, the heat transfer temperature difference firstly increased and then decreased; the curve was smooth. The maximum and minimum value was $9.9 \pm 0.4^{\circ} \mathrm{C}$ and $3.6 \pm 0.4^{\circ} \mathrm{C}$, respectively, and the average value was 8.0 $\pm 0.4^{\circ} \mathrm{C}$. However, the heat transfer coefficient fluctuated obviously and had a foreseeable trend of first increased and then decreased based on the polynomial fitting.

Both the fluctuations of the heat transfer coefficient and the temperature difference between the top and the bottom 


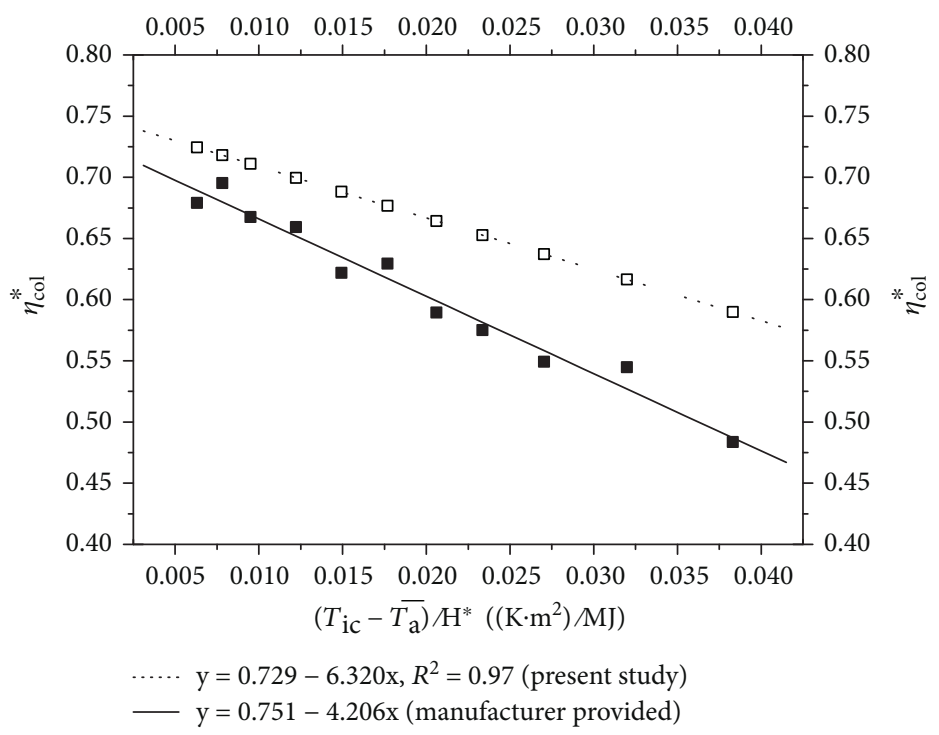

FIgURE 8: Graphical plot of the experimental results and the linear fitting.

TABLE 5: Solar collector performance compared with that in previous works.

\begin{tabular}{lcccc}
\hline System name & Collector type & $M^{\bullet}(\mathrm{kg} / \mathrm{s})$ & $\alpha$ & $U$ \\
\hline Present work & Flat plate & $/$ & 0.729 & 6.320 \\
Hussein [29] & Flat plate & $0.02 A$ & 0.735 & 6.67 \\
Aung and Li [30] & Flat plate & 0.0125 & 0.457 & 3.711 \\
Aung and Li [30] & Flat plate & 0.0292 & 0.618 & 4.420 \\
Aung and Li [30] & Flat plate & 0.0458 & 0.586 & 3.526 \\
Aung and Li [30] & Flat plate & 0.0625 & 0.571 & 3.967 \\
\hline
\end{tabular}

TABle 6: Daily experimental results (arranged by date).

\begin{tabular}{lcccccc}
\hline $\begin{array}{l}\text { Date }(\mathrm{D} / \\
\mathrm{M})\end{array}$ & $\begin{array}{c}T_{\mathrm{i}} \\
\left({ }^{\circ} \mathrm{C}\right)\end{array}$ & $\begin{array}{c}T_{\mathrm{f}} \\
\left({ }^{\circ} \mathrm{C}\right)\end{array}$ & $\begin{array}{c}\triangle T \\
\left({ }^{\circ} \mathrm{C}\right)\end{array}$ & $\begin{array}{c}\overline{T_{\mathrm{a}}} \\
\left({ }^{\circ} \mathrm{C}\right)\end{array}$ & $\begin{array}{c}H(\mathrm{M}) / \\
\left.\mathrm{m}^{2} \cdot \text { day }\right)\end{array}$ & $\eta_{\text {sys }}$ \\
\hline $17 / 12$ & 7.4 & 30.3 & 22.8 & 5.3 & 15.790 & 0.500 \\
$19 / 12$ & 7.9 & 28.4 & 20.5 & 7.5 & 14.099 & 0.504 \\
$23 / 12$ & 7.8 & 29.7 & 21.9 & 5.9 & 15.326 & 0.495 \\
$14 / 03$ & 10.8 & 42.5 & 31.7 & 17.6 & 20.356 & 0.540 \\
$24 / 03$ & 11.2 & 50.3 & 39.1 & 17.3 & 24.085 & 0.561 \\
$25 / 03$ & 11.5 & 49.7 & 38.2 & 22.7 & 20.518 & 0.582 \\
$26 / 03$ & 13.7 & 48.8 & 35.1 & 21.0 & 21.573 & 0.563 \\
$01 / 04$ & 15.4 & 52.2 & 36.8 & 22.4 & 23.058 & 0.552 \\
$03 / 04$ & 14.4 & 48.7 & 34.4 & 17.6 & 22.332 & 0.533 \\
$05 / 04$ & 15.3 & 46.9 & 31.5 & 22.0 & 19.527 & 0.558 \\
$06 / 04$ & 16.0 & 46.4 & 30.3 & 24.3 & 18.250 & 0.575 \\
$07 / 04$ & 17.5 & 47.8 & 30.3 & 24.4 & 18.588 & 0.564 \\
\hline
\end{tabular}

of the solar collector (as shown in Figure 6) are due to the oscillatory heat transfer characteristic of the LT [31]. When there is a high degree of superheat between the R600a liquid and the copper pipes, it caused intense nucleate boiling in the evaporation section/solar collector of the LT. The bubbles will grow bigger when they flow up along the copper pipe, which changed the quantity of R600a steam and then caused the oscillatory heat transfer. The oscillatory heat transfer makes the temperature fluctuate slightly, as well as the heat transfer coefficient.

4.2. Photothermal Performance of the Solar Collector. On the basis of GB/T 4271-2007 [32], test data obtained only when solar irradiation was larger than $700 \mathrm{~W} / \mathrm{m}^{2}$ were selected for analysis. The inlet temperature $\left(T_{i}\right)$, commonly used in curves for water-cooled units, was replaced by the inlet R600a temperature $\left(T_{i c}\right)$. The other parameters are given in Table 4. The linear fitting, which is calculated based on (2), is plotted in Figure 8. A curve of the collector that uses water as the working fluid is also provided for comparison.

The curve shows that the solar evaporator can provide a satisfactory photothermal performance, slightly lower than that of the water based, with absorption of 0.729 . The heat loss coefficient was 6.320, which was higher than that of the normal solar collector, because there was extra heat loss caused by the long connection pipes and devices. Although the modified wickless LT solar collector had a large heat loss coefficient in this study, it can work without any freezing problem and corrosion, and most importantly, it can be easily remolded. Therefore, the improvement shows great potential for solar application and can serve as a good substitute for the normal solar collector when it is used in an area with high latitude.

Table 5 presents the comparison of collector performance between the current study and previous works with natural-convection recirculation. The results show that the collector performance of the present study was very close to that found in the study of Hussein et al. [33], with a flow rate of $0.02 \mathrm{~A}$, and was better than that in the work of Nada et al. [34], under different flow rates. However, the heat loss ratio in the present study was bigger. Besides, the linear fitting results indicated that a reasonable similarity was obtained between the presented experimental results and those of 


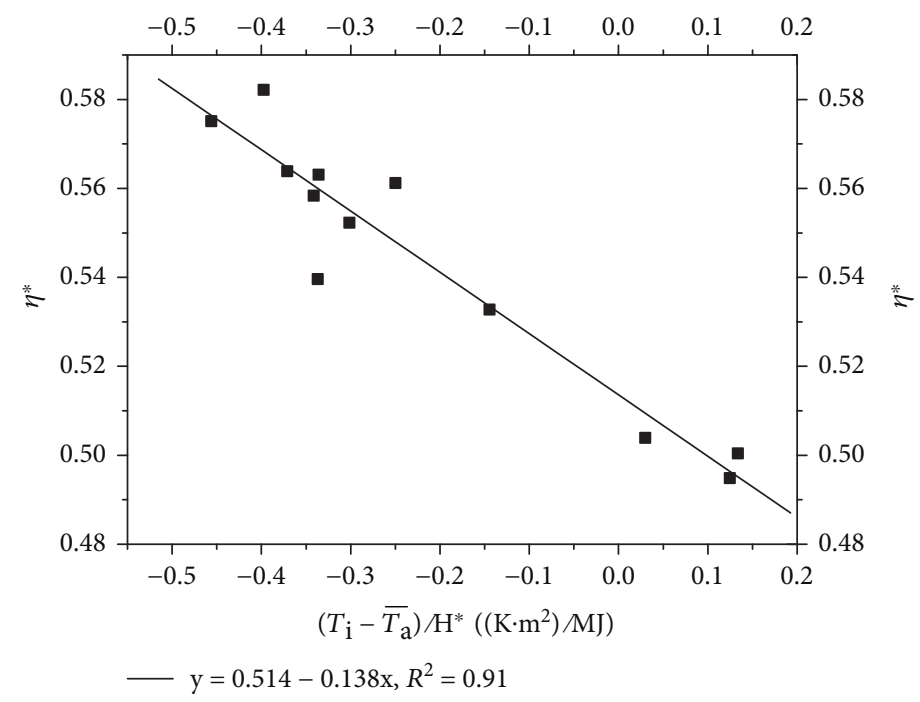

FIgURE 9: Graphical plot of the experimental results and the linear fitting.

TABle 7: System thermal performance compared with those in previous works.

\begin{tabular}{lcccc}
\hline System name & $A\left(\mathrm{~m}^{2}\right)$ & $M(\mathrm{~kg})$ & $\alpha$ & $U$ \\
\hline Present work & 1.82 & 150 & 0.514 & 0.138 \\
Chang et al. [37], B & 3.80 & 294 & 0.55 & 0.14 \\
Chang et al. [37], C & 3.71 & 287 & 0.54 & 0.15 \\
Chang et al. [37], D & 1.89 & 120 & 0.45 & 0.14 \\
\hline
\end{tabular}

other natural-convection recirculation two-phase collectors investigated, such as those by Hammad [35], M. Esen and H. Esen [14], and Rittidech and Wannapakne [36]. In summary, the forced wickless LT collector of the present work had a similar thermal performance compared to that of the other two-phase experiment assemblies, but its water tank had no position limitation. This feature indicates the promising prospect for solar application.

4.3. Thermal Performance of the System. To examine the overall performance and evaluate the daily performance of the system under different weather conditions, several tests were performed during winter and early spring in Hefei, China. Linear fitting based on (2) is conducted. Daily effective experimental results of the forced wickless LT-SWH system are listed in Table 6.

A wealth of information can be found in the experimental results detailed in Table 6 . The system can supply water with a temperature of almost $50^{\circ} \mathrm{C}$ during early spring in Hefei, and it was sufficient for domestic use. An efficiency of approximately $55 \%$, which is not less than that of a watercooled water heating system, was obtained. An efficiency of approximately 50\% was achieved even during winter. Besides, as mentioned before, no freezing problems occurred during the tests.

The plot of $\eta^{*}$ against $\left(T_{\mathrm{i}}-\overline{T_{\mathrm{a}}}\right) / H^{*}$ of the system, as well as the curve obtained under standard conditions with the use of water, is shown in Figure 9. Based on these data, the linear regression line is expressed as

$$
\eta=0.514-0.138 \frac{T_{\mathrm{i}}-\overline{T_{\mathrm{a}}}}{H^{*}},
$$

where 0.514 was the daily average thermal efficiency when the initial water temperature equals the daily average ambient temperature. Normally, the initial water temperature is larger than the daily average ambient temperature in winter, and this condition results in a low thermal efficiency. The overall heat loss coefficient of the system was 0.138 . Based on (2), the performance of the forced wickless LT-SWH under different solar irradiations, ambient temperatures, wind conditions, initial temperatures, and so on can be evaluated.

To the best of our knowledge, studies that examine the linear fitting of the system thermal performance of a twophase SWH system are scarce. A comparison of earlier works [33] with water as the working fluid and the present study is given in Table 7 . The results show that the forced wickless LT-SWH system had a similar thermal performance as the traditional SWH system. However, the proposed LT-SWH system has no corrosion and freezing problems during winter, and it has low heat loss at night due to the peculiarity of thermionic diode of LT. Above all, the proposed system demonstrates many advantages despite its low thermal efficiency and high heat loss efficiency. The system is therefore a good substitute for the normal water-based SWHs when it is used in a high-latitude area.

\section{Conclusion}

Compared to normal gravity LT-SWH, although there is additional power consumption, the location of the water tank of the forced-circulation wickless LT-SWH system becomes more freely. Long-term outdoor tests were conducted, and useful data were achieved in this study. The performance of 
the proposed wickless LT-SWH system and collector was presented. The conclusion can be drawn as the following:

(1) Based on the long-term field test data, the experimental fitting equations of the evaporation collector and the proposed system were presented. The proposed system and the solar evaporator achieved a satisfactory overall thermal performance. With the equation, the performance of the forced wickless LT-SWH system and the evaporation collector can be evaluated under different climatic conditions.

(2) The solar collector had an even temperature distribution as phase change occurred in the evaporation section of the wickless LT; the average temperature difference between the top and bottom and middle and bottom was $2.8 \pm 0.4^{\circ} \mathrm{C}$ and $1.1 \pm 0.4^{\circ} \mathrm{C}$, respectively.

\section{Nomenclature}

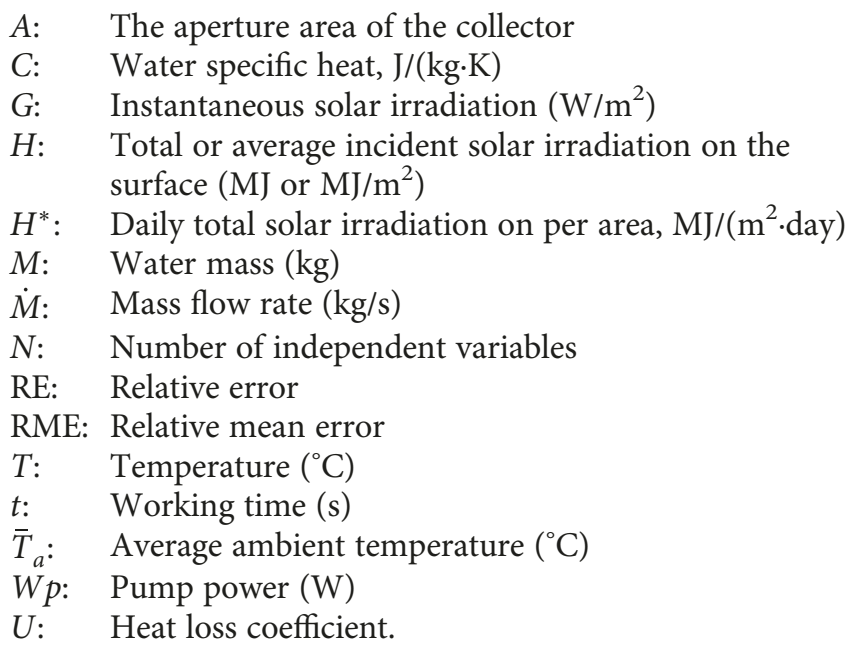

\section{Greek Symbols}

$\eta: \quad$ Efficiency

$\eta^{*}: \quad$ System photothermal efficiency

$\alpha$ : Typical photothermal efficiency

$\triangle T$ : Temperature difference $\left({ }^{\circ} \mathrm{C}\right)$.

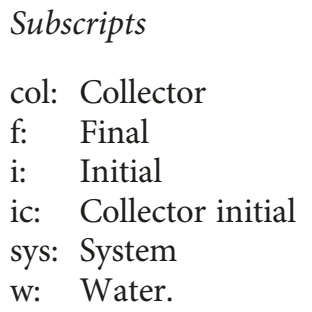

\section{Data Availability}

The data used to support the findings of this study are available from the corresponding author upon request.

\section{Conflicts of Interest}

The author declares no conflict of interests regarding the publication in this manuscript.

\section{Acknowledgments}

This work was sponsored by the Shanghai Sailing Program (18YF1409100) and Shanghai Local Capacity Building Program (18020501000), which are gratefully acknowledged by the author.

\section{References}

[1] The US Department of Energy, DOE/GO-10098-570, "Federal technology alert, solar water heating, a series of energy efficient guides prepared by the New Technology Demonstration Program," 2006, http://www.eren.doe.gov/femp/.

[2] S. Jaisankar, J. Ananth, S. Thulasi, S. T. Jayasuthakar, and K. N. Sheeba, "A comprehensive review on solar water heaters," Renewable and Sustainable Energy Reviews, vol. 15, no. 6, pp. 3045-3050, 2011.

[3] D. Y. Goswami, F. Kreith, and J. F. Kreider, Principles of Solar Engineering, Taylor \& Francis, USA, 2000.

[4] M. A. Sabiha, R. Saidur, S. Mekhilef, and O. Mahian, "Progress and latest developments of evacuated tube solar collectors," Renewable and Sustainable Energy Reviews, vol. 51, pp. 1038-1054, 2015.

[5] “The U.S. Department of Energy," 2013, http://energy.gov/ energysaver/articles/heat-transfer-fluids-solar-water- heatingsystems.

[6] M. Mochizuki, A. Akbarzadeh, and T. Nguyen, "A review of heat pipe practical applications and innovative opportunities application for global warming, heat pipes and solid sorption transformation: fundamentals and practical applications," in Heat Pipes and Solid Sorption Transformations, pp. 145-212, Taylor \& Francis/CRC Press, 2013.

[7] A. S. Zhuravlyov, L. L. Vasiliev, and L. L. Vasiliev Jr, "Horizontal vapordynamic thermosyphons. Fundamental and practical applications," Heat Pipe Science and Technology, An International Journal, vol. 4, no. 1-2, pp. 39-52, 2013.

[8] L. L. Vasiliev, L. L. Vassiliev Jr, M. I. Rabetsky et al., "Long horizontal vapordynamic thermosyphons for renewable energy sources," Heat Transfer Engineering, pp. 1-9, 2018.

[9] K.-H. Chien, Y.-T. Lin, Y.-R. Chen, K.-S. Yang, and C.-C. Wang, "A novel design of pulsating heat pipe with fewer turns applicable to all orientations," International Journal of Heat and Mass Transfer, vol. 55, no. 21-22, pp. 5722-5728, 2012.

[10] S. Launay, V. Sartre, and J. Bonjour, "Parametric analysis of loop heat pipe operation: a literature review," International Journal of Thermal Sciences, vol. 46, no. 7, pp. 621-636, 2007.

[11] D. Reay and P. Kew, Heat Pipe, Elsevier Ltd, 5th edition, 2006.

[12] R. S. Soin, K. S. Rao, D. P. Rao, and K. S. Rao, "Performance of flat plate solar collector with fluid undergoing phase chance," Solar Energy, vol. 23, no. 1, pp. 69-73, 1979.

[13] R. S. Soin, S. Raghuraman, and V. Murali, "Two-phase water heater model and long term performance," Solar Energy, vol. 38, no. 2, pp. 105-112, 1987. 
[14] M. Esen and H. Esen, "Experimental investigation of a twophase closed thermosyphon solar water heater," Solar Energy, vol. 79, no. 5, pp. 459-468, 2005.

[15] C. C. Chien, C. K. Kung, C. C. Chang, W. S. Lee, C. S. Jwo, and S. L. Chen, "Theoretical and experimental investigations of a two-phase thermosyphon solar water heater," Energy, vol. 36, no. 1, pp. 415-423, 2011.

[16] K. A. Joudi and A. A. Al-tabbakh, "Computer simulation of a two phase thermosyphon solar domestic hot water heating system," Energy Conversion and Management, vol. 40, no. 7, pp. 775-793, 1999.

[17] M. Arab, M. Soltanieh, and M. B. Shafii, "Experimental investigation of extra-long pulsating heat pipe application in solar water heaters," Experimental Thermal and Fluid Science, vol. 42, pp. 6-15, 2012.

[18] E. Mathioulakis and V. Belessiotis, "A new heat-pipe type solar domestic hot water system," Solar Energy, vol. 72, no. 1, pp. 13-20, 2002.

[19] H. M. S. Hussein, "Transient investigation of a two phase closed thermosyphon flat plate solar water heater," Energy Conversion and Management, vol. 43, no. 18, pp. 2479-2492, 2002.

[20] H. M. S. Hussein, "Optimization of a natural circulation two phase closed thermosyphon flat plate solar water heater," Energy Conversion and Management, vol. 44, no. 14, pp. 2341-2352, 2003.

[21] A. Ordaz-Flores, O. García-Valladares, and V. H. Gómez, "Findings to improve the performance of a two-phase flat plate solar system, using acetone and methanol as working fluids," Solar Energy, vol. 86, no. 4, pp. 1089-1098, 2012.

[22] X.-R. Zhang, Y. Zhang, and L. Chen, "Experimental study on solar thermal conversion based on supercritical natural convection," Renewable Energy, vol. 62, pp. 610-618, 2014.

[23] G. Pei, T. Zhang, Z. Yu, H. Fu, and J. Ji, "Comparative study of a novel heat pipe photovoltaic/thermal collector and a water thermosiphon photovoltaic/thermal collector," Proceedings of the Institution of Mechanical Engineers, Part A: Journal of Power and Energy, vol. 225, no. 3, pp. 271-278, 2011.

[24] M. V. Albanese, B. S. Robinson, E. G. Brehob, and M. Keith Sharp, "Simulated and experimental performance of a heat pipe assisted solar wall," Solar Energy, vol. 86, no. 5, pp. 1552-1562, 2012.

[25] X. Zhao, Z. Wang, and Q. Tang, "Theoretical investigation of the performance of a novel loop heat pipe solar water heating system for use in Beijing, China," Applied Thermal Engineering, vol. 30, no. 16, pp. 2526-2536, 2010.

[26] Z. Wang, Z. Duan, X. Zhao, and M. Chen, "Dynamic performance of a façade-based solar loop heat pipe water heating system," Solar Energy, vol. 86, no. 5, pp. 1632-1647, 2012.

[27] B. J. Huang and S. C. Du, "A performance test method of solar thermosyphon systems," Journal of Solar Energy Engineering, vol. 113, no. 3, p. 172, 1991.

[28] P. Gang, F. Huide, Z. Huijuan, and J. Jie, "Performance study and parametric analysis of a novel heat pipe PV/T system," Energy, vol. 37, no. 1, pp. 384-395, 2012.

[29] T. Zhang, G. Pei, Q. Zhu, and J. Ji, "Investigation on the optimum volume-filling ratio of a loop thermosyphon solar waterheating system," Journal of Solar Energy Engineering, vol. 138, no. 4, article 041006, 2016.

[30] N. Z. Aung and S. Li, "Numerical investigation on effect of riser diameter and inclination on system parameters in a two-phase closed loop thermosyphon solar water heater," Energy Conversion and Management, vol. 75, pp. 25-35, 2013.

[31] C. Yanze, Z. Yihui, and D. Xinwei, "An investigation of the heat-transfer fluctuation characteristics in gravity heat pipes and an exploration of methods for their restraint," Journal of Engineering for Thermal Energy \& Power, vol. 18, no. 4, pp. 334-336, 2003.

[32] GB/T 4271, "Test methods for the thermal performance of solar collectors," The Newest National Standard of China, Which Ruled the Test Method and the Calculation Program of the Solar Collector's Thermal Performance under Steady State and Dynamic State, 2007.

[33] H. M. S. Hussein, M. A. Mohamad, and A. S. El-Asfouri, "Transient investigation of a thermosyphon flat-plate solar collector," Applied Thermal Engineering, vol. 19, no. 7, pp. 789-800, 1999.

[34] S. A. Nada, H. H. El-Ghetany, and H. M. S. Hussein, "Performance of a two-phase closed thermosyphon solar collector with a shell and tube heat exchanger," Applied Thermal Engineering, vol. 24, no. 13, pp. 1959-1968, 2004.

[35] M. Hammad, "Experimental study of the performance of a solar collector cooled by heat pipes," Renewable Energy, vol. 36, no. 3, pp. 197-203, 1995.

[36] S. Rittidech and S. Wannapakne, "Experimental study of the performance of a solar collector by closed-end oscillating heat pipe (CEOHP)," Applied Thermal Engineering, vol. 27, no. 1112, pp. 1978-1985, 2007.

[37] J. M. Chang, J. S. Leu, M. C. Shen, and B. J. Huang, "A proposed modified efficiency for thermosyphon solar heating systems," Solar Energy, vol. 76, no. 6, pp. 693-701, 2004. 

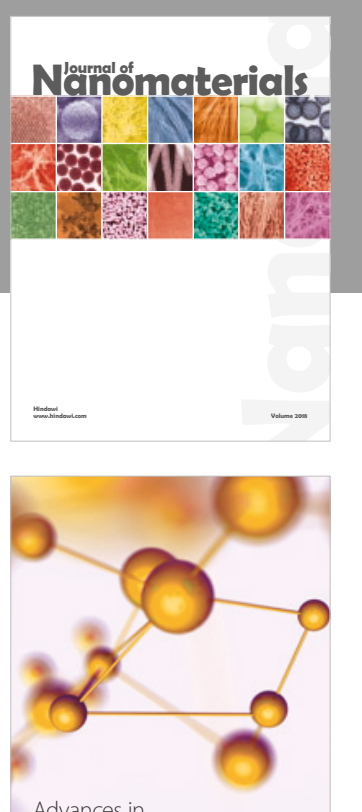

Physical Chemistry
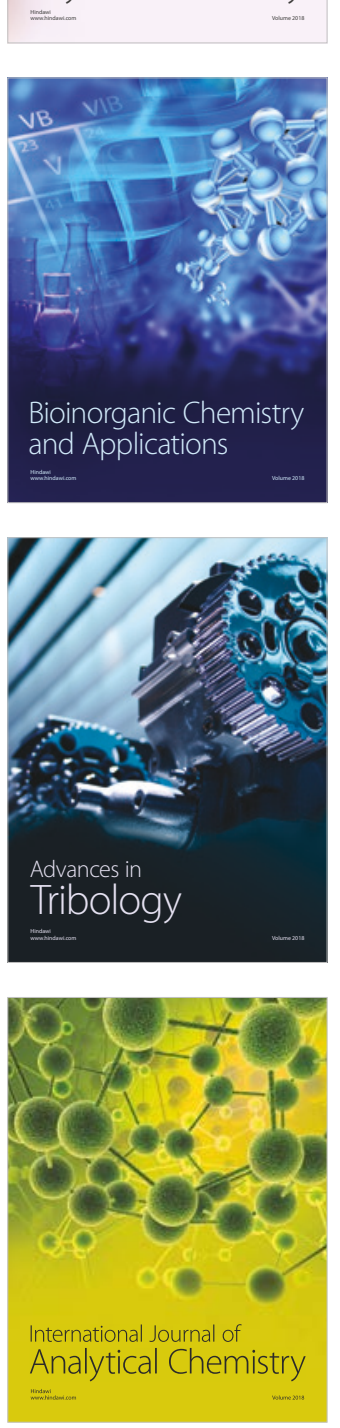

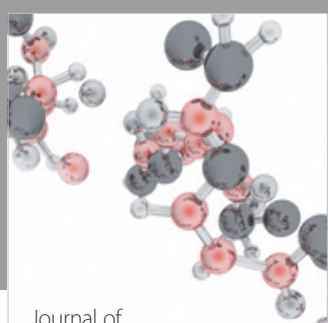

Analytical Methods

in Chemistry

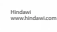

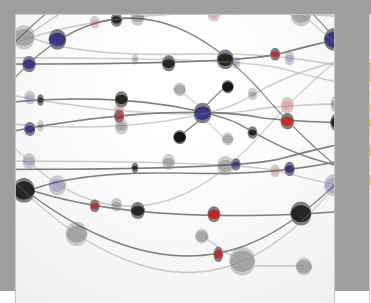

The Scientific World Journal

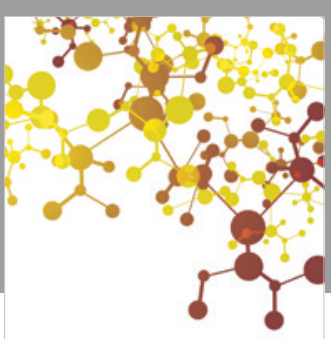

Journal of

Applied Chemistry
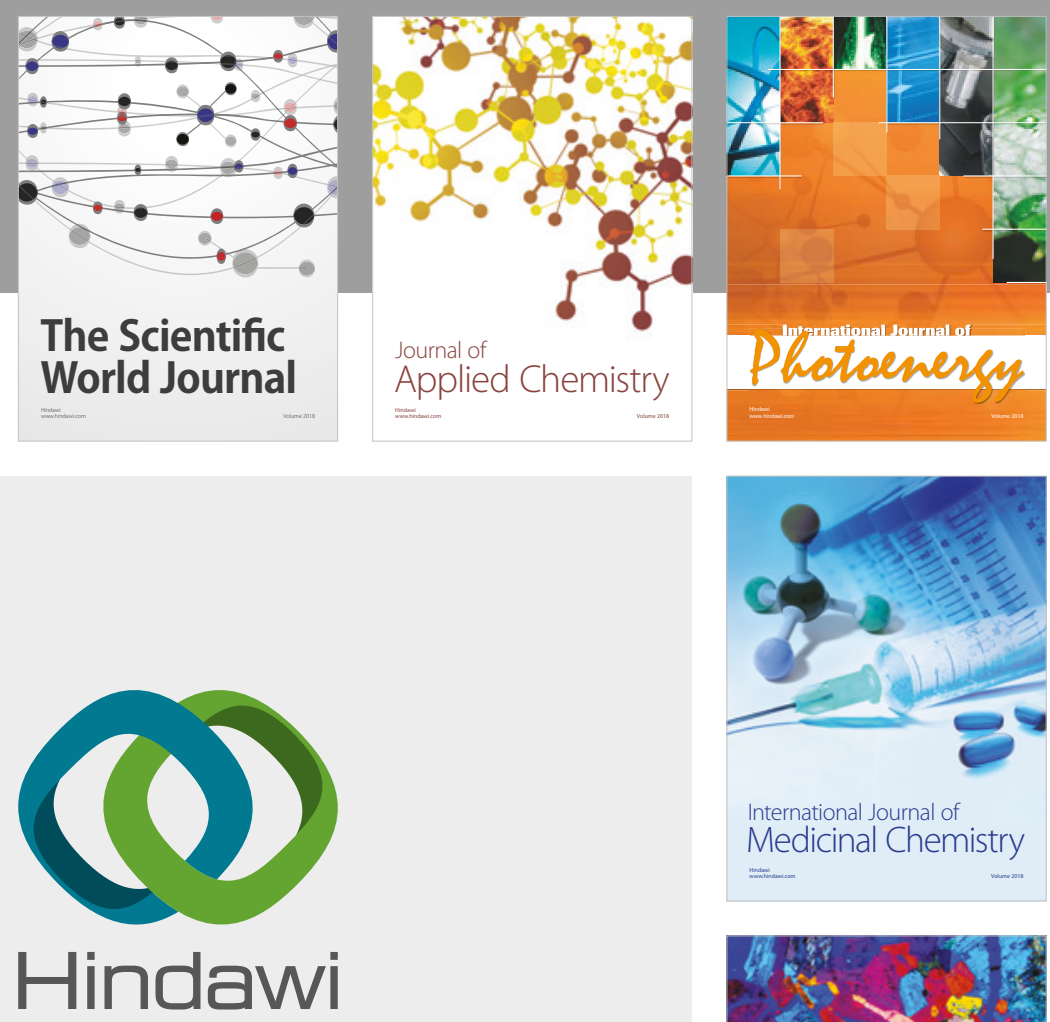

Submit your manuscripts at

www.hindawi.com
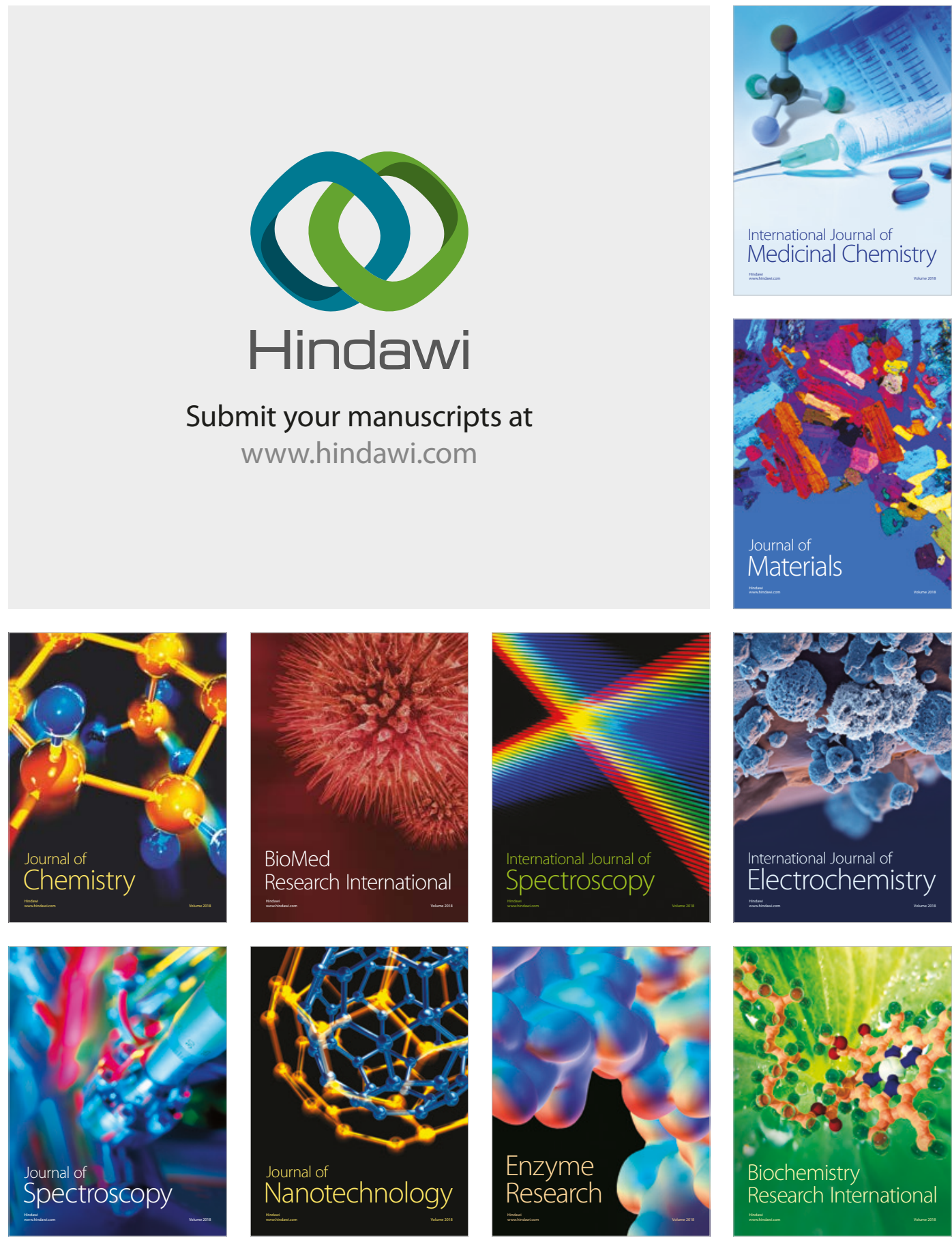
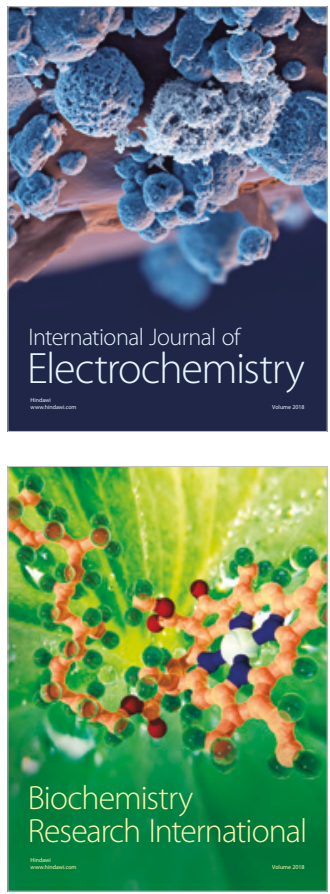